\title{
Superior survival with pediatric-style chemotherapy compared to myeloablative allogeneic hematopoietic cell transplantation in older adolescents and young adults with Ph-negative acute lymphoblastic leukemia in first complete remission: analysis from CALGB 10403 and the CIBMTR
}

\author{
Matthew J. Wieduwilt $\mathbb{D}^{1} \cdot$ Wendy Stock ${ }^{2} \cdot$ Anjali Advani $\mathbb{B}^{3} \cdot$ Selina Luger $\mathbb{C}^{4} \cdot$ Richard A. Larson $\mathbb{1}^{2} \cdot$ \\ Martin Tallman ${ }^{5} \cdot$ Frederick Appelbaum $^{6} \cdot$ Mei-Jie Zhang ${ }^{7,8} \cdot$ Khalid Bo-Subait $^{7} \cdot$ Hai-Lin Wang $^{7}$. \\ Vijaya Raj Bhatt $\mathbb{1}^{9} \cdot$ Bhagirathbhai Dholaria $\mathbb{1}^{10} \cdot$ Mary Eapen $^{7} \cdot$ Mehdi Hamadani $\mathbb{1}^{11} \cdot$ Omer Jamy $^{12}$. \\ Tim Prestidge $\mathbb{C}^{13} \cdot$ Michael Pulsipher $\mathbb{D}^{14} \cdot$ David Ritchie ${ }^{15} \cdot$ David Rizzieri ${ }^{16}$. Akshay Sharma $\mathbb{C}^{17} \cdot$ Pere Barba $\mathbb{C}^{18}$. \\ Brenda M. Sandmaier $\mathbb{D}^{19,20} \cdot$ Marcos de Lima $\mathbb{D}^{21} \cdot$ Partow Kebriaei $\mathbb{D}^{22} \cdot$ Mark Litzow $\mathbb{D}^{23} \cdot$ Wael Saber ${ }^{7}$. \\ Daniel Weisdorf $\mathbb{C}^{24}$
}

Received: 17 September 2020 / Revised: 28 January 2021 / Accepted: 25 February 2021 / Published online: 30 March 2021 (c) The Author(s) 2021. This article is published with open access

\begin{abstract}
Optimal post-remission therapy for adolescents and young adults (AYAs) with Ph-negative acute lymphoblastic leukemia (ALL) in first complete remission (CR1) is not established. We compared overall survival (OS), disease-free survival (DFS), relapse, and non-relapse mortality (NRM) for patients receiving post-remission therapy on CALGB 10403 to a cohort undergoing myeloablative (MA) allogeneic hematopoietic cell transplantation (HCT) in CR1. In univariate analysis, OS was superior with chemotherapy compared to MA allogeneic HCT (3-year OS $77 \%$ vs. $53 \%, P<0.001)$. In multivariate analysis, allogeneic HCT showed inferior OS (HR 2.00, 95\% CI 1.5-2.66, $P<0.001$ ), inferior DFS (HR 1.62, 95\% CI 1.25-2.12, $P<0.001$ ), and increased NRM (HR 5.41, 95\% CI 3.23-9.06, $P<0.001$ ) compared to chemotherapy. A higher 5-year relapse incidence was seen with chemotherapy compared to allogeneic HCT (34\% vs. $23 \%, P=0.011)$. Obesity was independently associated with inferior OS (HR 2.17, 95\% CI 1.63-2.89, $P<0.001$ ), inferior DFS (HR 1.97, 95\% CI 1.51-2.57, $P<0.001$ ), increased relapse $(1.84,95 \%$ CI 1.31-2.59, $P<0.001)$, and increased NRM (HR 2.10, 95\% CI 1.37-3.23, $P<0.001)$. For AYA ALL patients in CR1, post-remission therapy with pediatric-style chemotherapy is superior to MA allogeneic HCT for OS, DFS, and NRM.
\end{abstract}

\section{Introduction}

The optimal post-remission therapy for AYAs with Phnegative ALL in CR1 is not known in the era of pediatricinspired chemotherapy regimens with more intensive postremission therapy than traditional adult regimens. Previous studies suggested superiority of post-remission therapy with allogeneic HCT over chemotherapy. MRC UKALLXII/

Supplementary information The online version contains supplementary material available at https://doi.org/10.1038/s41375021-01213-5.

Matthew J. Wieduwilt

matthew.wieduwilt@gmail.com

Extended author information available on the last page of the article
E2993 compared traditional adult chemotherapy or autologous HCT to MA allogeneic HCT in patients aged 15-59 years with Ph-negative ALL. Overall survival (OS) was improved in standard-risk ALL patients with a donor, primarily due to more relapse in the no donor group [1]. However, individual studies in adults comparing allogeneic HCT to chemotherapy alone have not shown a clear benefit of allogeneic HCT although meta-analyses support allogeneic HCT in CR1 [2, 3]. A meta-analysis of 13 trials comparing allogeneic HCT to chemotherapy with or without autologous HCT concluded that the benefit of allogeneic HCT for patients with Ph-negative ALL in CR1 was limited to those under the age of 35 [2], the age group now commonly treated with pediatric-style chemotherapy. In this metanalysis, which included the UKALLXII/E2993 study, 5 -year OS for patients $<35$ years of age was $53.7 \%$, lower 
than the survival typically seen with pediatric-inspired chemotherapy in the AYA population [2, 4-8].

Pediatric-style chemotherapy may improve outcomes for AYAs with Ph-negative ALL [4-8]. A meta-analysis of 11 trials showed superior OS, event-free survival (EFS), and relapse rates in AYAs treated with pediatricinspired chemotherapy relative to conventional adult chemotherapy [9]. The DFCI Adult ALL Consortium reported on 74 patients aged 18-50 years with $\mathrm{Ph}-$ negative ALL treated with pediatric-style chemotherapy [10]. A 4-year EFS of $62 \%$ was observed. Seftel et al. compared the DFCI regimen to MA allogeneic HCT outcomes using data from the Center for International Blood and Marrow Transplant Research (CIBMTR) [11]. Relapse rates were similar between the two groups but pediatric-style chemotherapy was superior to allogeneic HCT for 4-year OS and DFS, due primarily to lower rates of NRM with chemotherapy. In multivariate analysis, allogeneic HCT was the only factor associated with inferior OS (HR 2.86, $P<0.0001$ ).

A single-arm, prospective, US Intergroup study led by the Alliance for Clinical Trials in Oncology (CALGB 10403) studied the feasibility of applying the pediatric COG AALL0232 standard-risk arm regimen to AYAs aged 16-39 years with Ph-negative ALL [12]. The 3-year EFS was $59 \%$ with a 3 -year OS of $73 \%$, an improvement compared to young adults treated with historical adult CALGB regimens [13]. Given the large size of the study and its enrollment of patients across the US, we used it as a model population to compare outcomes of pediatric-style postremission therapy to MA allogeneic HCT.

A major limitation of prior studies comparing allogeneic HCT to chemotherapy is that the post-remission chemotherapy was of lower intensity compared with current pediatric-style chemotherapy regimens. Pediatric-style postremission therapy may improve relapse rates with low NRM conceivably leading to superior survival relative to allogeneic HCT. This study was designed to compare OS, DFS, relapse, and NRM in patients aged 16-39 years with $\mathrm{Ph}$ negative ALL in CR1 undergoing post-remission therapy with pediatric-inspired chemotherapy on CALGB 10403 vs. MA allogeneic HCT. Results from this study directly inform the debate on the role of allogeneic HCT for AYA patients with Ph-negative ALL in CR1.

\section{Methods}

\section{Study population}

The chemotherapy cohort consisted of patients receiving postremission chemotherapy on CALGB 10403 (NCT00558519). Eligible patients from CALGB 10403 were patients aged
16-39 years with Philadelphia-chromosome/BCR-ABL1negative ALL in CR1 who started post-remission chemotherapy. The MA allogeneic HCT cohort consisted of patients aged 16-39 years with a diagnosis of Ph-negative ALL in CR1 undergoing post-remission therapy with a MA bone marrow or peripheral blood allogeneic HCT from a matched sibling, matched related, or unrelated donor (URD) in the U.S. from 11/1/2002 through 8/31/2012 reported to the CIBMTR. Patients receiving syngeneic, haploidentical, or umbilical cord blood HCT were excluded.

\section{Objectives and endpoints}

The start time for outcomes was the date of CR1. The primary objective was to compare OS between patients receiving postremission therapy with MA allogeneic HCT vs. chemotherapy. Secondary objectives included DFS, relapse rate, and NRM rate between the allogeneic HCT and chemotherapy cohorts. Additional secondary objectives included determination of patient and disease factors influencing outcomes of post-remission therapy using either approach. The primary endpoint of OS was defined as the time from CR1 to the last contact date or death from any cause. Secondary endpoints included NRM defined as time to death without evidence of leukemia recurrence with relapse as the competing risk, relapse was defined as the cumulative incidence of leukemia recurrence after CR1 with NRM as a competing risk, and DFS was defined as the time from CR1 to leukemia relapse or death. Surviving patients were censored at last time reported alive and in continued remission. Allogeneic HCT cohort endpoints included acute grade II-IV graft-versus-host disease (GVHD) fulfilling the Consensus criteria and chronic GVHD defined as the occurrence of symptoms in any organ diagnostic of chronic GVHD.

\section{Statistical analysis}

Patient-, disease-, and transplant-related factors were compared between treatment groups using the Chi-square test for categorical variables and the Wilcoxon two sample test for continuous variables. Comparing outcomes in the transplant and chemotherapy groups required adjustment for two sources of bias: differences in time to treatment/time to transplant and differences in baseline characteristics of patients. Starting from CR1, left-truncated analysis methods were used to address the first potential bias, that patients must survive in CR1 a sufficient length of time until transplant. At each time point $(t)$ in this model, the risk set in the chemotherapy cohort consists of all patients still under study, while the risk set in the transplant cohort includes only those whose waiting time to transplant was less than the current study time point $(t)$. The probabilities of DFS and OS were calculated using the left-truncated 
Kaplan-Meier estimator. Probabilities of NRM and relapse were generated using left-truncated cumulative incidence estimates to account for competing risks. The univariate probabilities of relapse and NRM were compared using the Gray's test [14]. To adjust for the differences in baseline characteristics, left-truncated Cox proportional hazards regression was used to compare the two treatment groups. Multivariate analysis factors included age, gender, race, body mass index, Karnofsky performance status, ALL immunophenotype, white blood cell count at diagnosis, cytogenetic risk group, extramedullary disease at diagnosis, and time to documentation of CR1 (Table 1). The assumption of proportional hazards for each factor in the Cox model was tested using time-dependent covariates. When the test indicated differential effects over time (nonproportional hazards), models were constructed breaking the post-transplant time course into two periods, using the maximized partial likelihood method to find the most appropriate breakpoint. A backward stepwise model selection approach was used to identify all significant risk factors. Each step of model building contained the main effect for treatment groups. Factors, which were significant at a $5 \%$ level, were kept in the final model. The potential interactions between main effect and all significant risk factors were tested. Adjusted probabilities of DFS and OS were generated from the final Cox models stratified on treatment and weighted averages of covariate values using the pooled sample proportion as the weight function. These adjusted probabilities estimate likelihood of outcomes in populations with similar prognostic factors. Chemotherapy patients who received a transplant during CR1 were censored for OS at time of transplant $(N=20)$. HCT-related variables were not analyzed in the multivariate since they are not relevant in the chemotherapy cohort. The HCT cohort included a planned sub-analysis of donor effect evaluating HLA-identical siblings vs. well-matched (8/8) URD or partially matched (7/8) URD and no differences were seen in outcomes between the groups. Acute and chronic GVHD was included following HCT as timedependent covariates.

\section{Results}

\section{Patient populations}

The chemotherapy cohort consisted of 263 patients treated at 60 centers with a median age of 24 years (range 17-39) and median follow up of 65 months (range 1-109). The MA allogeneic HCT cohort consisted of 217 patients treated at 72 centers with a median age of 27 years (range 16-40) with a median follow up of 98 months (range 23-179). Significant differences between the chemotherapy and allogeneic HCT cohorts included race (Caucasian, 75\% vs. $89 \%$ ), Karnofsky performance score ( $\geq 80,91 \%$ vs. $88 \%$ ), white blood cell count at diagnosis, cytogenetics, extramedullary disease at diagnosis (present, $48 \%$ vs. $19 \%$ ), and weeks from diagnosis to documentation of CR1 (median 4.4 vs. 7.6 weeks). A large majority of patients in the allogeneic HCT cohort patients received TBI-based conditioning $(92 \%)$ from a well-matched related or URD (79\%) within 6 months of documented CR1 (86\%). Graft source was peripheral blood for $73 \%$ of transplants. GVHD prophylaxis was principally calcineurin inhibitor with methotrexate based $(70 \%)$ with in vivo T-cell depletion used in $21 \%$ of transplants. Population characteristics are summarized in Table 1.

\section{Outcomes in univariate analysis}

In univariate analysis, no differences in OS, relapse, or NRM, were observed between allogeneic HCT and chemotherapy at 100 days after the initiation of post-remission therapy. At 3 and 5 years, OS was superior with chemotherapy compared to allogeneic HCT (3-year OS 77\% vs. $53 \%, P<0.001$, 5-year OS $66 \%$ vs. $47 \%, P<0.001)$. Also, 3- and 5-year DFS was superior with chemotherapy compared to allogeneic HCT (3-year DFS 68\% vs. 50\%, $P$ $<0.001,5$-year DFS $58 \%$ vs. $44 \%, P=0.004)$. Non-relapse mortality was lower with chemotherapy compared to allogeneic HCT (3-year NRM 6\% vs. 24\%, $P=<0.001$. 5-year NRM $8 \%$ vs. $29 \%, P<0.001)$. Cumulative relapse at 5 years was significantly higher in the chemotherapy cohort relative to the allogeneic HCT cohort (5-year relapse incidence $34 \%$ vs. $23 \%, P=0.011$ ). Univariate outcomes are summarized in Table 2 and Fig. 1.

\section{Multivariate outcomes by treatment modality}

For the entire study population $(N=480)$, OS was worse with allogeneic HCT (HR 2.00, 95\% CI 1.5-2.66, $P<$ $0.001)$ and obesity (BMI $\geq 30 \mathrm{~kg} / \mathrm{m}^{2}$, HR $2.17,95 \%$ CI $1.63-2.89, P<0.001)$. Post-remission therapy with allogeneic HCT led to inferior DFS (HR 1.62, 95\% CI $1.25-2.12, P<0.001)$ and higher risk of NRM (HR 5.41, 95\% CI 3.23-9.06, $P<0.001)$. In the early post-remission period ( $\leq 15$ months after CR1), relapse was more likely with allogeneic HCT (HR 1.78, 95\% CI 1.10-2.88, $P=$ 0.02) while beyond 15 months after CR1 relapse was more likely in the chemotherapy cohort (HR $0.34,95 \%$ CI $0.19-0.62, P<0.001)$. In addition to worse OS, obesity was associated with inferior DFS (HR 1.97, 95\% CI 1.51-2.57, $P<0.001$ ), more relapse (HR 1.84, 95\% CI $1.31-2.59, P<0.001$ ), and more NRM (HR 2.10, 95\% CI $1.37-3.23, P<0.001)$. We included a planned multivariate sub-analysis comparing outcomes of 
Table 1 Population characteristics.

\begin{tabular}{|c|c|c|c|}
\hline Characteristic & CIBMTR HCT & CALGB 10403 & $P$ value \\
\hline No. of patients & 217 & 263 & \\
\hline No. of centers & 72 & 60 & \\
\hline Follow-up-median (min-max) & $98(24-173)$ & $65(1-109)$ & \\
\hline \multicolumn{4}{|l|}{ Age at CR1, Years-no. (\%) $0.08^{\mathrm{a}}$} \\
\hline Median (min-max) & $27(16-40)$ & $24(17-39)$ & \\
\hline $16-20$ & $49(23)$ & $66(25)$ & \\
\hline $21-29$ & $94(43)$ & $132(50)$ & \\
\hline $30-39$ & $74(34)$ & $65(25)$ & \\
\hline Gender—no. (\%) & & & $0.51^{\mathrm{a}}$ \\
\hline Male & $140(65)$ & $162(62)$ & \\
\hline Female & $77(35)$ & $101(38)$ & \\
\hline Race-no. $(\%)$ & & & $<0.001^{\mathrm{b}}$ \\
\hline Caucasian & $193(89)$ & $197(75)$ & \\
\hline Other & $24(11)$ & $41(16)$ & \\
\hline Unknown/missing & 0 & $25(10)$ & \\
\hline BMI-no. $(\%)$ & & & $0.55^{\mathrm{a}}$ \\
\hline Not obese, $\mathrm{BMI}<30$ & $154(71)$ & $180(68)$ & \\
\hline Obese, $\mathrm{BMI} \geq 30$ & $63(29)$ & $83(32)$ & \\
\hline $\begin{array}{l}\text { Karnofsky performance score- } \\
\text { no. }(\%)\end{array}$ & & & $<0.001^{\mathrm{b}}$ \\
\hline$<80$ & $12(6)$ & $23(9)$ & \\
\hline$\geq 80$ & $192(88)$ & $240(91)$ & \\
\hline Missing & $13(6)$ & 0 & \\
\hline Immunophenotype- -no. (\%) & & & $0.09^{\mathrm{a}}$ \\
\hline T-cell & $43(20)$ & $65(25)$ & \\
\hline B-cell & $169(78)$ & $197(75)$ & \\
\hline Unspecified & $5(2)$ & $1(0)$ & \\
\hline $\begin{array}{l}\text { White blood count at diagnosis } \\
\left(\times 10^{9}\right) \_ \text {no. }(\%)\end{array}$ & & & $0.05^{\mathrm{a}}$ \\
\hline B-cell, $<30$ & $119(55)$ & $157(60)$ & \\
\hline B-cell, $>30$ & $50(23)$ & $40(15)$ & \\
\hline T-cell, $<100$ & $36(17)$ & $48(18)$ & \\
\hline T-cell, $>100$ & $7(3)$ & $17(6)$ & \\
\hline Unspecified, $<30$ & $1(0)$ & 0 & \\
\hline Unspecified, 30-100 & $3(1)$ & 0 & \\
\hline Unspecified, $>100$ & $1(0)$ & 0 & \\
\hline Missing & 0 & $1(0)$ & \\
\hline Cytogenetics—no. (\%) & & & $<0.001^{\mathrm{a}}$ \\
\hline Normal & $88(41)$ & $57(22)$ & \\
\hline Poor & $35(16)$ & $63(24)$ & \\
\hline Other & $68(31)$ & $39(15)$ & \\
\hline Missing & $26(12)$ & $104(40)$ & \\
\hline $\begin{array}{l}\text { Extramedullary disease at } \\
\text { diagnosis-no. }(\%)\end{array}$ & & & $<0.001^{\mathrm{a}}$ \\
\hline No & $176(81)$ & $137(52)$ & \\
\hline Yes & $41(19)$ & $126(48)$ & \\
\hline CNS envolvement & $11(5)$ & $27(10)$ & \\
\hline $\begin{array}{l}\text { Time to achieve CR1, weeks- } \\
\text { no. }(\%)\end{array}$ & & & $<0.001^{\mathrm{a}}$ \\
\hline Median (min-max) & $7.6(1.3-56)$ & $4.4(2.3-14.4)$ & \\
\hline$\leq 4$ weeks & $35(16)$ & $25(10)$ & \\
\hline $4-8$ weeks & $82(38)$ & $234(89)$ & \\
\hline$>8$ weeks & $100(46)$ & $4(2)$ & \\
\hline \multicolumn{4}{|l|}{ Transplant characteristics } \\
\hline \multicolumn{4}{|c|}{ Time from CR1 to HCT, months-no. (\%) } \\
\hline Median (min-max) & $3.3(0.2-18.8)$ & & \\
\hline$<6$ months & $186(86)$ & & \\
\hline
\end{tabular}

Table 1 (continued)

\begin{tabular}{|c|c|}
\hline Characteristic & CIBMTR HCT CALGB $10403 P$ value \\
\hline $6-12$ months & $30(14)$ \\
\hline$>12$ months & $1(0)$ \\
\hline $\begin{array}{l}\text { TBI given for conditioning- } \\
\text { no. }(\%)\end{array}$ & $199(92)$ \\
\hline \multicolumn{2}{|l|}{ Donor type-no. $(\%)$} \\
\hline HLA-identical sibling & $75(35)$ \\
\hline Other related & $4(2)$ \\
\hline Well-matched unrelated & $93(43)$ \\
\hline Partially matched unrelated & $39(18)$ \\
\hline Mis-matched unrelated & $6(3)$ \\
\hline $\begin{array}{l}\text { Donor age, years-median } \\
(\min -\max )\end{array}$ & $34(19-59)$ \\
\hline \multicolumn{2}{|l|}{ Donor/recipient gender-no. $(\%)$} \\
\hline $\mathrm{F} / \mathrm{M}$ & $49(23)$ \\
\hline Others & $168(77)$ \\
\hline \multicolumn{2}{|c|}{ Donor/recipient CMV match—no. $(\%)$} \\
\hline$+1-$ & $71(33)$ \\
\hline$-1+$ & $57(26)$ \\
\hline$-1-$ & $34(16)$ \\
\hline$+1+$ & $52(24)$ \\
\hline Missing & $3(1)$ \\
\hline \multicolumn{2}{|l|}{ Graft type-no. (\%) } \\
\hline Bone marrow & $58(27)$ \\
\hline Peripheral blood & $159(73)$ \\
\hline \multicolumn{2}{|l|}{ Year of transplant-no. $(\%)$} \\
\hline $2002-2005$ & $93(43)$ \\
\hline $2006-2008$ & $60(28)$ \\
\hline 2009-2012 & $64(29)$ \\
\hline \multicolumn{2}{|l|}{ GVHD prophylaxis-no. $(\%)$} \\
\hline Ex-vivo or CD34 selection & $10(5)$ \\
\hline Tac + MTX \pm others & $109(50)$ \\
\hline $\mathrm{CSA}+\mathrm{MTX} \pm$ others & $42(19)$ \\
\hline Others & $52(24)$ \\
\hline Missing & $4(2)$ \\
\hline $\begin{array}{l}\text { T-cell depletion (ATG/ } \\
\text { Alemtuzumab)—no. }(\%)\end{array}$ & $45(21)$ \\
\hline
\end{tabular}

Bold denotes variables included in regression models. Poor: complex ( $\geq 3$ abnormalities), $t(9 ; 22), t(4 ; 11), t(8 ; 14), t(14 ; 18)$, hypodiploid $(<46)$; normal: no abnormality; other: any abnormality not in poor. Others:_ATG + CsA + MTX + MMF + ursodiol $(n=1), \quad$ ATG + tacrolimus \pm others $(n=7), \quad$ corticosteroid $+\mathrm{CsA} \pm$ others $\quad(n=3)$, cortisosteroid + tacroimus \pm others $(n=5)$, CsA + tacrolimus $(n=1)$, CsA + MMF $(n=3)$, CsA + MTX + MMF $(n=1)$, tacrolimus $(n=$ $3)$, tacrolimus + sirolimus \pm others $(n=15)$, tacrolimus $+\mathrm{MMF} \pm$ others $(n=10), \mathrm{MMF}+$ sirolimus $(n=1)$, MTX $(n=2)$.

${ }^{a}$ Hypothesis testing: Pearson chi-square test.

${ }^{\mathrm{b}}$ Hypothesis testing: Fisher exact test.

HLA-identical siblings and well-matched (8/8) URDs to the chemotherapy cohort but findings were similar to the complete transplant cohort. Multivariate outcomes are summarized in Table 3. In addition, multivariate analysis evaluating outcomes by cytogenetic risk (standard vs. poor) and HCT time period (2002-2006 vs. 2007-2012) showed similar results to the full study population (Supplementary Tables 1 and 2). 
Table 2 Univariate estimates for allogeneic HCT vs. chemotherapy.

\begin{tabular}{|c|c|c|c|c|c|}
\hline \multirow[t]{2}{*}{ Outcome } & \multicolumn{2}{|c|}{$\begin{array}{l}\text { Myeloablative } \\
\text { allogeneic HCT } \\
\text { (CIBMTR) }\end{array}$} & \multicolumn{3}{|c|}{$\begin{array}{l}\text { Pediatric chemotherapy } \\
\text { (CALGB 10403) }\end{array}$} \\
\hline & $N$ & $\begin{array}{l}\text { Probability, \% } \\
(95 \% \text { CI })\end{array}$ & $N$ & $\begin{array}{l}\text { Probability, \% } \\
(95 \% \text { CI) }\end{array}$ & $P$ \\
\hline $\begin{array}{l}\text { Overall } \\
\text { survival }\end{array}$ & 217 & & 263 & & $<0.001$ \\
\hline 100-day & & $95(88-99) \%$ & & $99(98-100) \%$ & 0.090 \\
\hline 1-year & & $72(65-79) \%$ & & $91(87-94) \%$ & $<0.001$ \\
\hline 3-year & & $53(46-60) \%$ & & $77(71-82) \%$ & $<0.001$ \\
\hline 5-year & & $47(40-54) \%$ & & $66(60-72) \%$ & $<0.001$ \\
\hline Relapse & 215 & & 256 & & 0.016 \\
\hline 100-day & & $0(0-2) \%$ & & $0(0-2) \%$ & 0.909 \\
\hline 1-year & & $11(7-16) \%$ & & $10(7-15) \%$ & 0.803 \\
\hline 3-year & & $21(16-27) \%$ & & $26(21-32) \%$ & 0.216 \\
\hline 5-year & & $23(17-29) \%$ & & $34(28-40) \%$ & 0.011 \\
\hline $\begin{array}{l}\text { Non-relapse } \\
\text { mortality }\end{array}$ & 215 & & 256 & & $<0.001$ \\
\hline 100-day & & $1(0-3) \%$ & & $1(0-2) \%$ & 0.536 \\
\hline 1-year & & $17(12-22) \%$ & & $4(2-7) \%$ & $<0.001$ \\
\hline 3-year & & $24(19-30) \%$ & & $6(3-9) \%$ & $<0.001$ \\
\hline 5-year & & $29(23-35) \%$ & & $8(5-12) \%$ & $<0.001$ \\
\hline $\begin{array}{l}\text { Disease-free } \\
\text { survival }\end{array}$ & 215 & & 256 & & $<0.001$ \\
\hline 100-day & & $95(88-99) \%$ & & $99(97-100) \%$ & 0.133 \\
\hline 1-year & & $66(59-73) \%$ & & $85(80-89) \%$ & $<0.001$ \\
\hline 3-year & & $50(43-57) \%$ & & $68(62-73) \%$ & $<0.001$ \\
\hline 5-year & & $44(38-51) \%$ & & $58(52-65) \%$ & 0.004 \\
\hline
\end{tabular}

\section{Discussion}

Allogeneic HCT is indicated for Ph-negative ALL in CR1 based on trials using donor vs. no donor comparisons. UKALLXII/ECOG2993 showed improved survival with allogeneic HCT for adults aged 15-54 years with $\mathrm{Ph}$ negative ALL when compared to chemotherapy or autologous HCT (5-year OS $54 \%$ vs. $44 \%, P=0.007$ ) [1]. Gupta et al. found in a meta-analysis of 13 studies that allogeneic HCT for Ph-negative ALL benefited patients under age 35 years relative to traditional adult chemotherapy (Odd ratio of death $=0.79 ; 95 \% \mathrm{CI}, 0.70-0.90, P=$ 0.0003 ) [2]. However, pediatric-style regimens with more intensive post-remission therapy appear to have improved outcomes for AYA patients with Ph-negative ALL in retrospective comparisons [4-9]. A retrospective analysis of GRAALL2003/2005 studies showed that, for adults aged 15-55 years with high-risk Ph-negative ALL, allogeneic HCT demonstrated equivalent survival to pediatric-style chemotherapy in patients MRD-negative after induction and a survival benefit for patients MRD-positive after induction
[15]. The finding suggested that allogeneic HCT is a safe and effective option for all high-risk ALL patients regardless of MRD status.

To help clarify the role of allogeneic HCT in AYAs with Ph-negative ALL in CR1 treated with pediatric-style chemotherapy, Seftel et al. compared 108 adults 18-50 years of age treated with the Dana-Farber Consortium pediatric-style regimen at 13 centers in the northeastern US and eastern Canada to a CIBMTR allogeneic HCT cohort [11]. No difference in relapse was observed but higher NRM, lower DFS, and lower OS was seen with allogeneic HCT. Notably, allogeneic HCT was the only multivariate factor predictive of shorter OS (HR 3.12 (1.99-4.90), $P<0.0001$ ). Limitations of the study included a chemotherapy cohort with small numbers of patients from a select and geographically limited group of centers compared to the CIBMTR cohort. As such, the generalizability of the findings is unclear but support deferring allogeneic HCT for relapse in AYAs receiving pediatric-style post-remission therapy.

CALGB 10403 was a national, single-arm, Phase II study of the feasibility of treating patients aged 16-39 years with Ph-negative ALL with the standard-risk arm of the COG AALL0232 regimen [12, 13]. The study analyzed 295 patients at 60 centers across the United States, among which 263 achieved complete remission after initial treatment. Comparing this patient cohort to a contemporary CIBMTR allogeneic HCT cohort, we found improved OS with pediatric-style post-remission chemotherapy relative to MA allogeneic HCT with an absolute 5-year survival improvement of $19 \%$. Although overall relapse was higher with pediatric-style chemotherapy, the high NRM with allogeneic HCT had a large negative impact on OS. In multivariate analysis, allogeneic HCT was significantly associated with reduced OS, reduced DFS, and increased NRM. Differences in relapse between the cohorts seen in our study versus the Seftel et al. study [11] may be related to differences in chemotherapy regimens, patient compliance, patient eligibility, and/or statistical power. In contrast to the high-risk Ph-negative ALL patients treated on the GRAALL2003/2005, patients treated with CALGB 10403 consolidation had significantly improved survival relative to allogeneic HCT patients. The different patient populations or possibly the different post-remission regimens may explain the superiority of chemotherapy over allogeneic HCT seen in our study.

In pediatric patients with ALL receiving chemotherapy, obesity is associated with increased NRM, increased relapse, and decreased OS [16-22], but a negative effect of obesity has not been routinely seen in adults [23]. CALGB 10403 found that obese AYA patients with ALL had significantly reduced DFS compared with nonobese patients [13]. We found that obesity was associated with decreased 
Fig. 1 Overall survival, disease-free survival, relapse, and non-relapse mortality from first complete remission (CR1) of chemotherapy (chemo) and allogeneic HCT (HCT) cohorts. Upper left, adjusted overall survival; upper right, adjusted diseasefree survival; lower left, cumulative incidence of relapse; lower right, cumulative incidence of non-relapse mortality.
Figure. Survival and CIF Curves

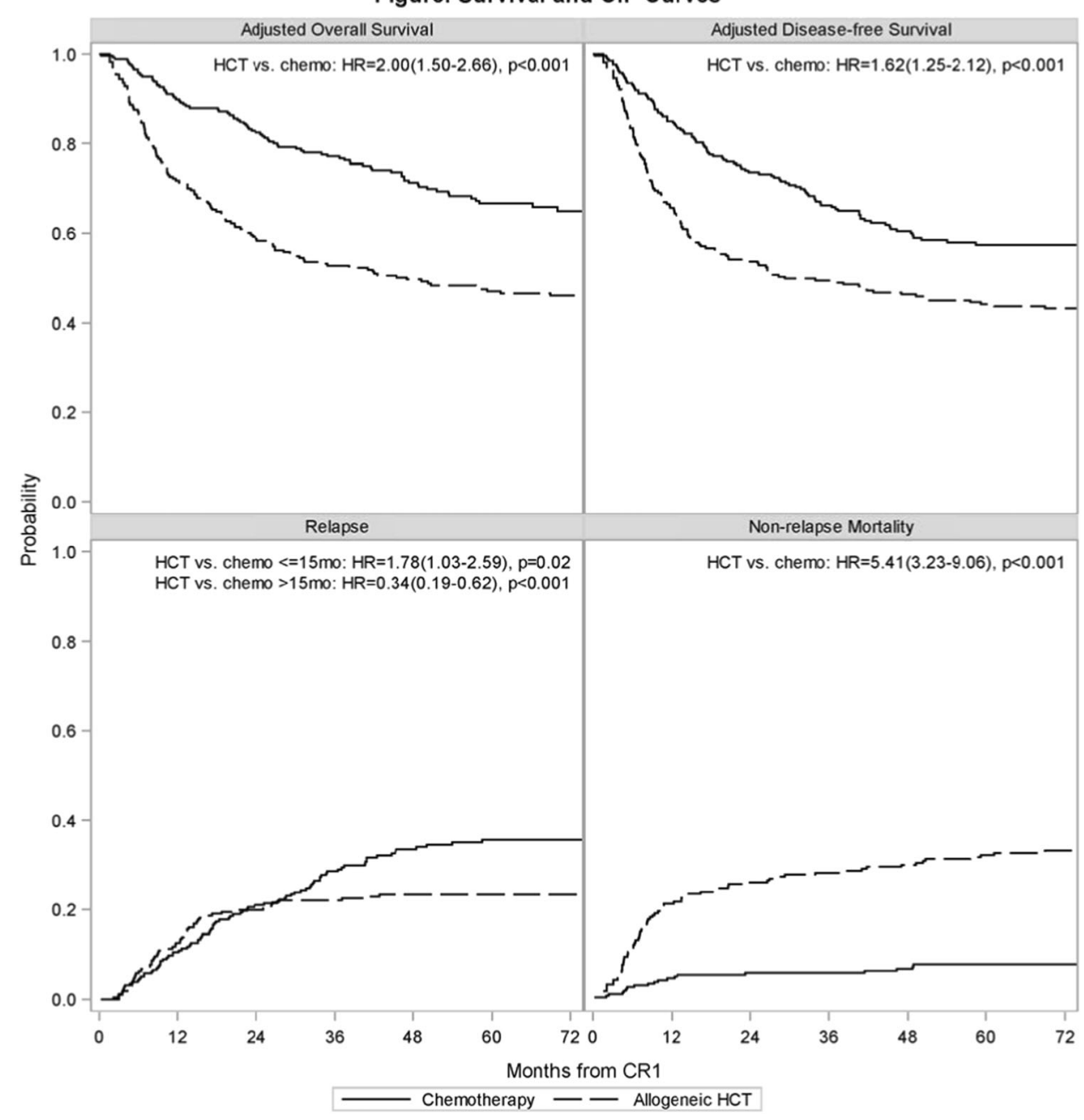

OS and DFS in this study and the effect was seen in both the chemotherapy and allogeneic HCT cohorts. The difference was due to both increased relapse and increased NRM in obese patients. The curative potential of both chemotherapy and allogeneic HCT appears to be reduced in obese AYAs with ALL. Adipocytes appear to protect ALL cells from the toxic effects of chemotherapy including daunorubicin, by sequestration and metabolism, and asparaginase, through the release of glutamine [24-29]. NRM was also higher in obese patients perhaps owing to lower tolerability of treatment due to comorbidities, high doses of therapy dosed on body-surface area, or alternative pharmacokinetics or pharmacodynamics of drugs in the obese population. Prior large studies focusing of obesity in adults undergoing allogeneic HCT for hematologic malignancies have not found a deleterious effect of obesity on OS or relapse with some studies showing increased NRM [30-34]. It is possible that the negative effect of obesity on OS and relapse seen here may be unique to ALL and the AYA population.
One limitation of this study is that minimal information on MRD in both cohorts prevented meaningful comparisons between MRD-positive and MRD-negative patients in both cohorts. As such, the role of allogeneic HCT vs. chemotherapy in MRD-positive patients could not be explored. In addition, it is possible that the allogenic HCT cohort had higher risk features not identified here, including higher rates of MRD positivity, although if true this did not translate into high relapse rates in the allogeneic HCT cohort and would not be expected to affect NRM, the primary reason for the reduced survival seen with allogeneic HCT relative to pediatric-style chemotherapy. The chemotherapy regimens received prior to allogeneic HCT in the transplant cohort were also not available and this may affect relapse rates and possibly NRM. Again, however, relapse rates were low with allogeneic HCT and superior to chemotherapy whereas NRM was substantially higher with allogeneic HCT, an outcome less likely to be impacted by prior treatment with ALL-directed chemotherapies relative to the chemotherapy cohort. Another limitation is the lack 
Table 3 Multivariate analysis.

\begin{tabular}{|c|c|c|c|}
\hline Outcomes & $N$ & HR $(95 \%$ CI $)$ & $P$ value \\
\hline \multicolumn{4}{|l|}{ Overall survival } \\
\hline \multicolumn{4}{|l|}{ Main effect } \\
\hline Chemotherapy & 261 & Reference & \\
\hline Allogeneic HCT & 217 & $\begin{array}{l}2.00 \\
(1.50-2.66)\end{array}$ & $<0.001$ \\
\hline \multicolumn{4}{|l|}{ Body mass index $\left(\mathrm{kg} / \mathrm{m}^{2}\right)$} \\
\hline$<30$ & 332 & Reference & \\
\hline$\geq 30$ & 146 & $\begin{array}{l}2.17 \\
(1.63-2.89)\end{array}$ & $<0.001$ \\
\hline \multicolumn{4}{|l|}{ Disease-free survival } \\
\hline \multicolumn{4}{|l|}{ Main effect } \\
\hline Chemotherapy & 261 & Reference & \\
\hline Allogeneic HCT & 215 & $\begin{array}{l}1.62 \\
(1.25-2.12)\end{array}$ & $<0.001$ \\
\hline \multicolumn{4}{|l|}{ Body mass index $\left(\mathrm{kg} / \mathrm{m}^{2}\right)$} \\
\hline$<30$ & 331 & Reference & \\
\hline$\geq 30$ & 145 & $\begin{array}{l}1.97 \\
(1.51-2.57)\end{array}$ & $<0.001$ \\
\hline \multicolumn{4}{|l|}{ Relapse } \\
\hline Allogeneic HCT vs. chemotherapy $\leq 15$ months after CR 1 & & $\begin{array}{l}1.78 \\
(1.10-2.88)\end{array}$ & 0.02 \\
\hline Allogeneic HCT vs. chemotherapy $>15$ months after CR 1 & & $\begin{array}{l}0.34 \\
(0.19-0.62)\end{array}$ & $<0.001$ \\
\hline \multicolumn{4}{|l|}{ Body mass index $\left(\mathrm{kg} / \mathrm{m}^{2}\right)$} \\
\hline$<30$ & 331 & Reference & \\
\hline$\geq 30$ & 145 & $\begin{array}{l}1.84 \\
(1.31-2.59)\end{array}$ & $<0.001$ \\
\hline \multicolumn{4}{|l|}{ Non-relapse mortality } \\
\hline \multicolumn{4}{|l|}{ Main effect } \\
\hline Chemotherapy & 261 & Reference & \\
\hline Allogeneic HCT & 215 & $\begin{array}{l}5.41 \\
(3.23-9.06)\end{array}$ & $<0.001$ \\
\hline \multicolumn{4}{|l|}{ Body mass index $\left(\mathrm{kg} / \mathrm{m}^{2}\right)$} \\
\hline$<30$ & 331 & Reference & \\
\hline$\geq 30$ & 145 & $\begin{array}{l}2.10 \\
(1.37-3.23)\end{array}$ & $<0.001$ \\
\hline
\end{tabular}

of testing for the Ph-like phenotype and IKAROS mutation/ loss in the allogeneic HCT cohort. Although traditional high-risk cytogenetic features had no impact on outcomes, we were unable to assess if patients with Ph-like ALL may benefit from allogeneic HCT in CR1. Notable difference in the cohorts included extramedullary disease at diagnosis and longer time to documentation of CR1 in the allogeneic HCT cohort. Outside a formal clinical trial, documentation of extramedullary disease may be incomplete and the timing of remission assessments may vary based on treatment regimen used and post-induction marrow assessments, which in the transplant cohort were not determined by trial timepoints. Last, changes in treatment modalities, addition of new therapeutic agents, and improvements in supportive care may have changed relapse rates and NRM in both populations since 2012.

For AYAs with Ph-negative ALL in CR1, we conclude that AYAs receiving post-remission therapy with pediatricstyle chemotherapy for Ph-negative ALL in CR1 should not routinely undergo allogeneic HCT. Allogeneic HCT is warranted for patients refractory to or relapsing after pediatric-style regimens and may be warranted for high-risk
MRD-positive patients in CR1, although more study is needed. Obesity in AYAs with ALL warrants further investigation as a potentially modifiable factor that negatively impacted survival.

Acknowledgements CIBMTR Support List: The CIBMTR is supported primarily by Public Health Service U24CA076518 from the National Cancer Institute (NCI), the National Heart, Lung and Blood Institute (NHLBI) and the National Institute of Allergy and Infectious Diseases (NIAID); U24HL138660 from NHLBI and NCI; U01HL128568 from the NHLBI; HHSH250201700006C, and HHSH250201700007C from the Health Resources and Services Administration (HRSA); and N00014-18-1-2850, N00014-18-1-2888, and N00014-20-1-2705 from the Office of Naval Research. Additional federal support is provided by P01CA111412, R01CA152108, R01CA215134， R01CA218285， R01CA231141， R01AI128775, R01HL126589, R01HL129472, R01HL130388, R01HL131731, U01AI069197, U01AI126612, and BARDA. Support is also provided by Be the Match Foundation, Boston Children's Hospital, Dana-Farber, St. Baldrick's Foundation, Stanford University, the Medical College of Wisconsin the National Marrow Donor Program, and from the following commercial entities: AbbVie; Actinium Pharmaceuticals, Inc.; Adaptive Biotechnologies; Adienne SA; Allovir, Inc.; Amgen Inc.; Angiocrine Bioscience; Astellas Pharma US; AstraZeneca; Atara Biotherapeutics, Inc.; bluebird bio, Inc.; Bristol-Myers Squibb Co.; Celgene Corp.; CSL Behring; CytoSen Therapeutics, Inc.; DaiichiSankyo Co., Ltd.; Gamida-Cell, Ltd.; Genentech Inc; HistoGenetics, Inc.; Incyte Corporation; Janssen Biotech, Inc.; Jazz Pharmaceuticals, Inc.; Johnson \& Johnson; Kiadis Pharma; Kite, a Gilead Company; Kyowa Kirin; Legend Biotech; Magenta Therapeutics; Mallinckrodt LLC; Merck \& Company, Inc.; Merck Sharp \& Dohme Corp.; Millennium, the Takeda Oncology Co.; Miltenyi Biotec, Inc.; Novartis Pharmaceuticals Corporation; Omeros Corporation; Oncoimmune, Inc.; Orca Biosystems, Inc.; Pfizer, Inc.; Pharmacyclics, LLC; Sanofi Genzyme; Shire; Sobi, Inc.; Stemcyte; Takeda Pharma; Terumo BCT; Viracor Eurofins; Vor Bio Pharma; Xenikos BV. The views expressed in this article do not reflect the official policy or position of the National Institute of Health, the Department of the Navy, the Department of Defense, Health Resources and Services Administration (HRSA), or any other agency of the U.S. Government. This research was supported by a training grant from the National Institutes of Health, Clinical Pharmacoepidemiology training grant (Grant No. T32-GM075766 to CWE) and the Alex's Lemonade Stand Foundation (CWE). CIBMTR supports accessibility of research in accord with the National Institutes of Health (NIH) Data Sharing Policy and the National Cancer Institute (NCI) Cancer Moonshot Public Access and Data Sharing Policy. The CIBMTR only releases de-identified datasets that comply with all relevant global regulations regarding privacy and confidentiality.

Additional contributing co-authors from the writing committee Abhinav Deol, Ajoy Dias, Alexandra Gomez-Arteaga, Alison Loren, Amer Beitinjaneh, Antonio Jimenez, Arnon Nagler, Ayman Saad, B. Mona Wirk, Betty Hamilton, Biju George, Bipin Savani, Brenda Cooper, Brian Friend, Bruce Camitta, Celalettin Ustun, Cesar Freytes, Christen Ebens, Christopher Kanakry, David Valcarcel, Dipenkumar Modi, Dorothy Pan, Edmund Waller, Edwin Horwitz, Eric Huselton, Gary Schiller, Geoffrey Uy, George Yaghmour, Giancarlo Fatobene, Gregory Hale, Guillermo J. Ruiz Arguelles, Haydar Frangoul, Hemant Murthy, Hillard Lazarus, Hisham Abdel-Azim, Hongtao Liu, Ian Nivison-Smith, Ibrahim Ahmed, Ibrahim Aldoss, James Gajewski, Jan Cerny, Jeannine McCune, Jean-Yves Cahn, Jignesh Dalal, Joerg Halter, John Raegan, John Wagner, Jong Wook Lee, Joseph Maakaron, Kalyan Nadiminti, Kirk Schultz, Lazaros Lekakis, Lena Winestone, Leo F. Verdonck, Lori Muffly, Lynn Savoie, Madiha 
Iqbal, Mahmoud ALjurf, Manish Gandhi, Marc Bierings, Marjolein van der Poel, Matthew Seftel, Maxim Norkin, Maxwell Krem, Melhem Solh, Michael Boyiadzis, Michael Byrne, Michael Grunwald, Michael Verneris, Miguel Angel Diaz, Minoo Battiwalla, Mitchell Cairo, Mitchell Sabloff, Mohamed A. Kharfan-Dabaja, Monzr M. Al Malki, Nasheed M. Hossain, Natasha Kekre, Nathan Sunita, Neel Bhatt, Neil Palmisiano, Nelli Bejanyan, Nelson Chao, Olakekan Oluwole, Olle Ringden, Pashna Munshi, Passweg Jakob, Paul Castillo Caro, Peter Wiernik, Rammurti Kamble, Ran Reshef, Reinhold Munker, Reshma Ramlal, Richard Larson, Richard Lin, Richard Maziarz, Richard Olsson, Robert Peter Gale, Robert Soiffer, Roni Shouval, Rory Shallis, Ryan Cassaday, Ryotaro Nakamura, Saar Gill, Sachiko Seo, Sagar Patel, Samer Al-Homsi, Samer Srour, Saurabh Chhabra, Scott Solomon, Shahinaz Gadalla, Shahrukh Hashmi, Sherif Badawy, Siddhartha Ganguly, Taiga Nishihori, Talha Badar, Usama Gergis, Vaibhav Agrawal, Vera Ulrike Bacher, Yahveth Cantero Fortiz, Yasuyuki Arai, Yoshihiro Inamoto, Youjin Wang.

\section{Compliance with ethical standards}

Conflict of interest PBP reports Advisory from CELGENE-BMS, Advisory from NOVARTIS, Advisory from KITE-GILEAD, Advisory from AMGEN, outside the submitted work. MT reports personal fees from Miami Cancer Symposium, personal fees from NCCN, personal fees from UC Davis, personal fees from Mayo Clinic, personal fees from American Society of Hematology, personal fees from New Orleans, personal fees from ASCO, personal fees from Vanderbilt University, personal fees from Targeted Oncology, personal fees from Indy, personal fees from Emirates Hematology Society, personal fees from German AML Cooperative Group, personal fees from Penn State Cancer Institute, personal fees from prIME Oncology, personal fees from HammersmithHospital, personal fees from EHA Congress, personal fees from National Institute of Health/National Heart, Lung and Blood Institute, personal fees from International Symposium, personal fees from National Comprehensive Cancer Network, personal fees from TRM Oncology, personal fees from Medscape, personal fees from Sylvester Comprehensive Cancer Center, personal fees from ESH, personal fees from Chinese Medical Association, personal fees from Rambam Health Care Campus and Shaare Zedek Medical Center, personal fees from AMEH, grants from AbbVie, grants from Cellerant, grants from Orsenix, grants from ADC Therapeutics, grants from Biosight, grants from Glycomimetics, grants from Rafael Pharmaceuticals, grants from Amgen, Advisory Board from AbbVie, Advisory Board from BioLineRx, Advisory Board from Daiichi-Sankyo, Advisory Board from Orsenix, Advisory Board from KAHR, Advisory Board from Rigel, Advisory Board from Nohla, Advisory Board from Delta Fly Pharma, Advisory Board from Tetraphase, Advisory Board from Oncolyze, Advisory Board from Jazz Pharma, Advisory Board from Roche, Advisory Board from Biosight, Advisory Board from Novartis, Royalties from UpToDate, outside the submitted work. SL reports honoraria from Daiichi-Sankyo, Pfizer, Bristol-Myers Squibb, Acceleron, Agios, Loxo Oncology. SL reports institutional research support from Onconova, Kura, Hoffman La Roche, Ariad, Biosight, outside the submitted work. DRit reports grants from Amgen Australia, grants from Takeda Pharmaceuticals, grants from BMS Australia, outside the submitted work. DRiz reports personal fees from Amgen, personal fees from Kite, personal fees from AROG, personal fees from Pharmacyclics, personal fees from Seattle Genetics, personal fees from Pfizer, personal fees from Novartis, personal fees from Sanofi-Aventis, personal fees from Incyte, personal fees from Gilead, personal fees from Jazz, consulting and presentation to FDA for biosimilar review from Celltron/Teva, consulting and Advisory Board from Mustang, consulting from Bayer, research support, consultant, Speakers Bureau, Advisory Board from Stemline, personal fees from Celegene, outside the submitted work. MdL reports grants from Pfizer, grants from
Celgene, personal fees from Kadmon, personal fees from Pfizer, personal fees from Incyte, personal fees from BMS, outside the submitted work. RAL reports personal fees from Amgen, personal fees from AstraZeneca, personal fees from Agios, personal fees from CVS/ Caremark, personal fees and clinical trials from Celgene, personal fees from Delta Fly, personal fees from Epizyme, personal fees and clinical trials from Novartis, personal fees from Takeda, clinical trials from Astellas, clinical trials from Cellectis, clinical trials from Daiichi-Sankyo, clinical trials from Rafael Pharmaceuticals, clinical trials from Forty Seven, outside the submitted work. DW reports grants from Incyte, personal fees from FATE Therapeutics, outside the submitted work. AA reports grants from Novartis, grants from Abbvie, grants from Macrogenics, grants and personal fees from Glycomimetics, grants and personal fees from Pfizer, grants and personal fees from Amgen, personal fees from Seattle Genetics, personal fees from Kite Pharmaceuticals, during the conduct of the study. MP reports personal fees from Novartis, grants and personal fees from Miltenyi, grants from Adaptive, personal fees from Mesoblast, personal fees from Jasper, personal fees from Bellicum, outside the submitted work. WSt reports grants from NCI, during the conduct of the study. AS reports salary support from Vertex Pharmaceuticals/CRISPR Therapeutics paid to the institution, non-financial support from Novartis, non-financial support from Magenta Therapeutics, outside the submitted work. He is the principal investigator of a clinical trial for gene therapy of sickle cell disease sponsored by Vertex Pharmaceuticals/CRISPR Therapeutics. The sponsor provides funding for the clinical trial, which includes salary support paid to his institution. This is not related in any way to this work product. He also has research collaboration with Novartis, Magenta Therapeutics, and Bluebird Bio for which he is not financially compensated in any way. VRB reports personal fees from Agios, grants and personal fees from Incyte, personal fees from Takeda, personal fees from Partner Therapeutics, personal fees from Omeros, grants and personal fees from Abbvie, grants from Jazz, grants from National Marrow Donor Program, drug support for a trial from Oncoceutics, personal fees from Partnership for health analytic research, LLC, grants, personal fees and educational grant to institution from Pfizer, personal fees from CSL Behring, grants from Tolero Pharmaceuticals, personal fees from Rigel Pharmaceuticals, educational grant to institution from Novartis, outside the submitted work. BD reports Research support from Jenssen, Takeda, and Angiocrine as well as consultancy from Celgene/Juno. MJW, FA, M-JZ, KB-S, H-LW, ME, MH, OJ, TP, BMS, ML, and WS declare no competing financial interests.

Publisher's note Springer Nature remains neutral with regard to jurisdictional claims in published maps and institutional affiliations.

Open Access This article is licensed under a Creative Commons Attribution 4.0 International License, which permits use, sharing, adaptation, distribution and reproduction in any medium or format, as long as you give appropriate credit to the original author(s) and the source, provide a link to the Creative Commons license, and indicate if changes were made. The images or other third party material in this article are included in the article's Creative Commons license, unless indicated otherwise in a credit line to the material. If material is not included in the article's Creative Commons license and your intended use is not permitted by statutory regulation or exceeds the permitted use, you will need to obtain permission directly from the copyright holder. To view a copy of this license, visit http://creativecommons. org/licenses/by/4.0/.

\section{References}

1. Goldstone AH, Richards SM, Lazarus HM, Tallman MS, Buck G, Fielding $\mathrm{AK}$, et al. In adults with standard-risk acute 
lymphoblastic leukemia, the greatest benefit is achieved from a matched sibling allogeneic transplantation in first complete remission, and an autologous transplantation is less effective than conventional consolidation/maintenance chemotherapy in all patients: final results of the International ALL Trial (MRC UKALL XII/ECOG E2993). Blood. 2008;111:1827-33.

2. Gupta V, Richards S, Rowe J. Allogeneic, but not autologous, hematopoietic cell transplantation improves survival only among younger adults with acute lymphoblastic leukemia in first remission: an individual patient data meta-analysis. Blood. 2013;121:339-50.

3. Pidala, J, Diulbegovic, B, Anasetti, C, Kharfab-Dabajam M, Kumar A. Allogeneic hematopoietic cell transplantation for adult acute lymphoblastic leukemia (ALL) in first complete remission. Cochrane Database Syst Rev. 2011;2011:CD008818.

4. Boissel N, Auclerc MF, Lheritier V, Perel Y, Thomas X, Leblanc $\mathrm{T}$, et al. Should adolescents with acute lymphoblastic leukemia be treated as old children or young adults? Comparison of the French FRALLE-93 and LALA-94 trials. J Clin Oncol. 2003;21:774-80.

5. de Bont JM, Holt B, Dekker AW, van der Does-van den Berg A, Sonneveld P, Pieters R.Significant difference in outcome for adolescents with acute lymphoblastic leukemia treated on pediatric vs adult protocols in the Netherlands. Leukemia. 2004;18:2032-5.

6. Ramanujachar R, Richards S, Hann I, Goldstone A, Mitchell C, Vora A, et al. Adolescents with acute lymphoblastic leukaemia: outcome on UK national paediatric (ALL97) and adult (UKALLXII/E2993) trials. Pediatr Blood Cancer. 2007;48:254-61.

7. Stock W, La M, Sanford B, Bloomfield C, Vardiman JW, Gaynon $\mathrm{P}$, et al.What determines the outcomes for adolescents and young adults with acute lymphoblastic leukemia treated on cooperative group protocols? A comparison of Children's Cancer Group and Cancer and Leukemia Group B studies. Blood. 2008;112:1646-54.

8. Toft N, Birgens H, Abrahamsson J, Griskevicius L, Hallbook H, Heyman M, et al. Results of NOPHO ALL2008 treatment for patients aged 1-45 years with acute lymphoblastic leukemia. Leukemia. 2018;32:606-15.

9. Ram R, Wolach O, Vidal L, Gafter-Gvili A, Shpilberg O, Raanani. Adolescents and young adults with acute lymphoblastic leukemia have a better outcome when treated with pediatricinspired regimens: systematic review and meta-analysis. Am J Hematol. 2012;87:472-8.

10. DeAngelo DJ, Stevenson KE, Dahlberg SE, Silverman LB, Couban S, Supko JG, et al. Long-term outcome of a pediatricinspired regimen used for adults aged 18-50 years with newly diagnosed acute lymphoblastic leukemia. Leukemia. 2015;29:526-34.

11. Seftel MD, Neuberg D, Zhang MJ, Wang H-L, Ballen KK, Bergeron J, et al. Pediatric-inspired therapy compared to allografting for Philadelphia chromosome-negative adult ALL in first complete remission. Am J Hematol. 2016;91:322-9.

12. Larsen EC, Devidas M, Chen S, Salzar WL, Raetz EA, Loh ML, et al. Dexamethasone and high-dose methotrexate improve outcome for children and young adults with high-risk b-acute lymphoblastic leukemia: a report from Children's Oncology Group Study AALL0232. J Clin Oncol. 2016;34:2380-8.

13. Stock W, Luger SM, Advani AS, Yin J, Harvey RC, Mullighan $\mathrm{CG}$, et al. A pediatric regimen for older adolescents and young adults with acute lymphoblastic leukemia: results of CALGB 10403. Blood. 2019;133:1548-59.

14. Gray, RJ. A class of K-sample tests for comparing the cumulative incidence of a competing risk. Ann Stat. 1988;16:1141-54.

15. Dhedin N, Huynh A, Maury S, Tabrizi R, Beldjord K, Asnafi V, et al. Role of allogeneic stem cell transplantation in adult patients with Ph-negative acute lymphoblastic leukemia. Blood. 2015;125:2486-96.
16. Butturini AM, Dorey FJ, Lange BJ, Henry DW, Gaynon PS, Fu C, et al. Obesity and outcome in pediatric acute lymphoblastic leukemia. J Clin Oncol. 2007;25:2063-9.

17. Gelelete CB, Pereira SH, Azevedo AMB, Thiago SL, Mundim M, Land MGP, et al. Overweight as a prognostic factor in children with acute lymphoblastic leukemia. Obesity. 2011;19:1908-11.

18. Ethier MC, Alexander S, Abla O, Green G, Lam R, Sung L. Association between obesity at diagnosis and weight change during induction and survival in pediatric acute lymphoblastic leukemia. Leuk Lymphoma. 2012;53:1677-81.

19. Orgel E, Sposto R, Malvar J, Seibel NL, Ladas E, Gaynon PS, et al. Impact on survival and toxicity by duration of weight extremes during treatment for pediatric acute lymphoblastic leukemia: a report from the Children's Oncology Group. J Clin Oncol. 2014;32:1331-7.

20. Denton, CC, Rawlins, YA, Oberley, MJ, Bhojwani, D, and Orgel, E. Predictors of hepatotoxicity and pancreatitis in children and adolescents with acute lymphoblastic leukemia treated according to contemporary regimens. Pediatr Blood Cancer. 2018;65. https:// doi.org/10.1002/pbc.26891.

21. Meenan CK, Kelly JA, Wang L, Ritchey AK, Maurer SH. Obesity in pediatric patients with acute lymphoblastic leukemia increases the risk of adverse events during pre-maintenance chemotherapy. Pediatr Blood Cancer. 2019;66:e27515.

22. Núñez-Enríquez JC, Gil-Hernández AE, Jiménez-Hernández E, Fajardo-Gutierrez A, Medina-Sanson A, Flores-Lujano J, et al. Overweight and obesity as predictors of early mortality in Mexican children with acute lymphoblastic leukemia: a multicenter cohort study. BMC Cancer. 2019;19:708.

23. Heiblig M, Elhamri M, Nicolini FE, Wattel E, Michallet M, Salles $\mathrm{G}$, et al. Effect of initial body mass index on survival outcome of patients with acute leukemia: a single-center retrospective study. Clin Lymphoma Myeloma Leuk. 2015;15:S7-13.

24. Behan JW, Yun JP, Proektor MP, Ehsanipour EA, Arutyunyan A, Moses AS, et al. Adipocytes impair leukemia treatment in mice. Cancer Res. 2009;69:7867-74.

25. Yun JP, Behan JW, Heisterkamp N, Butturini A, Klemm L, Ji L, et al. Diet-induced obesity accelerates acute lymphoblastic leukemia progression in two murine models. Cancer Prev Res. 2010;3:1259-64.

26. Pramanik R, Sheng X, Ichihara B, Heisterkamp N, Mittelman SD. Adipose tissue attracts and protects acute lymphoblastic leukemia cells from chemotherapy. Leuk Res. 2013;37:503-9.

27. Ehsanipour EA, Sheng X, Behan JW, Wang X, Butturini A, Avramis VI, et al. Adipocytes cause leukemia cell resistance to L-asparaginase via release of glutamine. Cancer Res. 2013;73:2998-3006.

28. Sheng X, Tucci J, Parmentier JH, Ji L, Behan JW, Heisterkamp N, et al. Adipocytes cause leukemia cell resistance to daunorubicin via oxidative stress response. Oncotarget. 2016;7:73147-59.

29. Sheng X, Parmentier JH, Tucci J, Pei H, Cortez-Toledo O, DieliConwright CM, et al. Adipocytes sequester and metabolize the chemotherapeutic daunorubicin. Mol Cancer Res. 2017;15:1704-13.

30. Le Blanc K, Ringdén O, Remberger M. A low body mass index is correlated with poor survival after allogeneic stem cell transplantation. Haematologica. 2003;88:1044-52.

31. Nikolousis E, Nagra S, Paneesha S, Delgado J, Holder K, Bratby $\mathrm{L}$, et al. Allogeneic transplant outcomes are not affected by body mass index (BMI) in patients with haematological malignancies. Ann Hematol. 2010;89:1141-5.

32. Navarro WH, Agovi MA, Logan BR, Ballen K, Bolwell BJ, Frangoul $\mathrm{H}$, et al. Obesity does not preclude safe and effective myeloablative hematopoietic cell transplantation (HCT) for acute myelogenous leukemia (AML) in adults. Biol Blood Marrow Transplant. 2010;16:1442-50. 
33. Aplenc R, Zhang MJ, Sung L, Zhu X, Ho VT, Cooke K, et al. Effect of body mass in children with hematologic malignancies undergoing allogeneic bone marrow transplantation. Blood. 2014;123:3504-11.
34. Fuji S, Takano K, Mori T, Eto T, Taniguchi S, Ohashi K, et al. Impact of pretransplant body mass index on the clinical outcome after allogeneic hematopoietic SCT. Bone Marrow Transplant. 2014;49:1505-12.

\section{Affiliations}

Matthew J. Wieduwilt $\mathbb{1}^{1} \cdot$ Wendy Stock ${ }^{2} \cdot$ Anjali Advani $\mathbb{1}^{3} \cdot$ Selina Luger $\mathbb{D}^{4} \cdot$ Richard A. Larson $\mathbb{1}^{2} \cdot$ Martin Tallman ${ }^{5} \cdot$ Frederick Appelbaum $^{6} \cdot$ Mei-Jie Zhang ${ }^{7,8} \cdot$ Khalid Bo-Subait $^{7} \cdot$ Hai-Lin Wang $^{7} \cdot$ Vijaya Raj Bhatt $\mathbb{1}^{9} \cdot$ Bhagirathbhai Dholaria $\mathbb{1}^{10} \cdot$ Mary Eapen $^{7} \cdot$ Mehdi Hamadani $\mathbb{D}^{11} \cdot$ Omer Jamy $^{12}$. Tim Prestidge $\mathbb{C}^{13} \cdot$ Michael Pulsipher $\mathbb{C}^{14} \cdot$ David Ritchie ${ }^{15}$. David Rizzieri ${ }^{16}$. Akshay Sharma $\mathbb{C}^{17} \cdot$ Pere Barba $\mathbb{C}^{18}$. Brenda M. Sandmaier $\mathbb{D}^{19,20} \cdot$ Marcos de Lima $\mathbb{D}^{21} \cdot$ Partow Kebriaei $\mathbb{D}^{22} \cdot$ Mark Litzow $\mathbb{D}^{23} \cdot$ Wael Saber ${ }^{7}$. Daniel Weisdorf $\mathbb{C}^{24}$

1 University of California, San Diego Medical Center, La Jolla, CA, USA

2 University of Chicago Medicine, Chicago, IL, USA

3 Cleveland Clinic, Taussig Cancer Institute, Cleveland, OH, USA

4 Abramson Cancer Center, University of Pennsylvania Medical Center, Philadelphia, PA, USA

5 Leukemia Service, Department of Medicine, Memorial Sloan Kettering Cancer Center, New York, NY, USA

6 Fred Hutchinson Cancer Research Center, Seattle, WA, USA

7 Center for International Blood and Marrow Transplant Research, Department of Medicine, Medical College of Wisconsin, Milwaukee, WI, USA

8 Division of Biostatistics, Institute for Health and Society, Medical College of Wisconsin, Milwaukee, WI, USA

9 The Fred and Pamela Buffett Cancer Center, University of Nebraska Medical Center, Omaha, NE, USA

10 Vanderbilt University Medical Center, Nashville, TN, USA

11 BMT and Cellular Therapy Program, Department of Medicine, Medical College of Wisconsin, Milwaukee, WI, USA

12 University of Alabama at Birmingham, Birmingham, AL, USA

13 Blood and Cancer Centre, Starship Children's Hospital, Auckland, New Zealand
14 Section of Transplantation and Cellular Therapy, Children's Hospital Los Angeles Cancer and Blood Disease Institute, USC Keck School of Medicine, Los Angeles, CA, USA

15 Peter MacCallum Cancer Centre and Royal Melbourne Hospital, Melbourne, Vic, Australia

16 Division of Hematologic Malignancies and Cellular Therapy, Duke University, Durham, NC, USA

17 Department of Bone Marrow Transplantation and Cellular Therapy, St. Jude Children's Research Hospital, Memphis, TN, USA

18 Vall Hebron University Hospital-Universitat Autonoma de Barcelona, Barcelona, Spain

19 Division of Medical Oncology, University of Washington, Seattle, WA, USA

20 Clinical Research Division, Fred Hutchinson Cancer Research Center, Seattle, WA, USA

21 Seidman Cancer Center, University Hospitals Case Medical Center, Cleveland, $\mathrm{OH}$, USA

22 Department of Stem Cell Transplantation, Division of Cancer Medicine, The University of Texas MD Anderson Cancer Center, Houston, TX, USA

23 Division of Hematology and Transplant Center, Mayo Clinic, Rochester, MN, USA

24 Division of Hematology, Oncology and Transplantation, Department of Medicine, University of Minnesota, Minneapolis, MN, USA 